\title{
Ефективність застосування тракції та кінезитерапії в лікуванні дегенеративних змін у поперековому відділі хребта
}

\author{
УДК 616.711:616-089.21+615.825
}

\section{Я. В. Фіщенко ${ }^{1}$, Л. Д. Катюкова ${ }^{1}$, В. В. Зінченко О. І. Баяндіна ${ }^{1}$, О. Б. Лазарєва²}

${ }^{1}$ ДУ «Інститут травматології та ортопедії НАМН України», Київ, Україна 2Національний університет фізичного виховання і спорту України, Київ, Україна

Резюме. Дегенеративно-дистрофічні процеси хребта є одними з найактуальніших проблем сучасної медицини. За даними ВООЗ, 2/3 населення планети страждають від болю в попереку. Мета. Дослідити ефективність застосування тракції та кінезитерапії в лікуванні дегенеративних змін у поперековому відділі хребта. Методи. Проведено аналіз обстеження та лікування 46 хворих з клінічними і морфологічними проявами гриж міжхребцевих дисків поперекового відділу хребта. Було застосовано методику апаратної тракції, після чого хворим із нейрокомпресійним больовим синдромом попереково-крижового відділу хребта проводили терапевтичні вправи. Висновок. Використання тракції в поєднанні з медикаментозним лікуванням, кінезитерапією у хворих зрілого віку з дегенеративними змінами хребта в поперековому відділі дозволяє підвищити ефективність лікування, що підтверджується результатами дослідження.

Ключові слова: поперековий відділ хребта, дегенеративні зміни, тракція, кінезитерапія.

\section{Эффективность применения тракции и кинезитерапии в лечении} дегенеративных изменений в поясничном отделе позвоночника Я. В. Фищенко, Л. Д. Катюкова, В. В. Зинченко, О. И. Баяндина, Е. Б. Лазарева

Резюме. Дегенеративно-дистрофические процессы позвоночника являются одними из наиболее актуальных проблем современной медицины. По данным ВОЗ, 2/3 населения земного шара страдают от боли в пояснице. Цель. Исследовать эффективность применения тракции и кинезитерапии в лечении дегенеративных изменений в поясничном отделе позвоночника. Методы. Проведен анализ обследования и лечения 46 больных с клиническими и морфологическими проявлениями грыж межпозвонковых дисков поясничного отдела позвоночника. Была использована методика аппаратной тракции, после чего больным с нейрокомпрессионным болевым синдромом пояснично-крестцового отдела позвоночника проводили терапевтические упражнения. Вывод. Использование тракции в сочетании с медикаментозным лечением, кинезитерапией у больных зрелого возраста с дегенеративными изменениями позвоночника в поясничном отделе позволяет повысить эффективность лечения, что подтверждается результатами исследования.

Ключевые слова: поясничный отдел позвоночника, дегенеративные изменения, тракция, кинезитерапия.

Effectiveness of application of traction and kinesitherapy in treatment of dehenerative changes in the lumbar spine

I. V. Fishchenko, L. D. Katiukova, V. V. Zinchenko, O. I. Baiandina, O. B. Lazarieva

Abstract. Objective. To study the effectiveness of traction and kinesitherapy in the treatment of degenerative changes in the lumbar spine. Methods. The analysis of examination and treatment of 46 patients with clinical and morphological manifestations of herniated intervertebral discs of 
the lumbar spine was carried out. The technique of instrumental traction was used, after which the patient was given therapeutic exercises. Conclusion. The use of traction in combination with medicinal treatment, kinesitherapy for adult patients with degenerative changes in the lumbar spine can increase the effectiveness of treatment, which is confirmed by the results of the study.

Keywords: lumbar spine, degenerative changes, traction, kinesitherapy.

Постановка проблеми. Аналіз останніх досліджень і публікацій. Остеохондроз хребта - одне з поширених захворювань опорнорухової системи. Дегенеративні зміни в хребті діагностують у $57 \%$ людей вже у віці 20-29 років. Частота їх швидко прогресує, досягаючи 90-95\% у віці 40-49 років, а у людей старше 60 років - у $100 \%$. Частка цієї патології у жінок становить $34,7 \%$, у чоловіків - 65,3 \% $[1,2,5]$. Нейрокомпресійний больовий синдром попереково-крижового відділу хребта може бути обумовлений такими станами: протрузіями та грижами міжхребцевих дисків, гіпертрофрією суглобових відростків на тлі спондилоартрозу, дегенеративним поперековим спінальним стенозом, дегенеративними десоормаціями хребта [7-9].

Існує безліч способів боротьби з такою недугою як остеохондроз хребта. У науково-методичній літературі широко висвітлено проблеми реабілітації пацієнтів з остеохондрозом $[3,4,6$, 10, 12].

Ефективність лікування залежить від своєчасного початку та комплексності. Комплексне консервативне лікування включає медикаментозну терапію, фрізичну терапію, масаж, фрізіотерапію, витягування (тракцію) хребта тощо.

Одним із провідних методів при нейрокомпресійному болю $є$ апаратна тракція хребта. Цей метод дозволяє ерективно і в короткі терміни здійснити реабілітаційні лікувальні заходи у пацієнтів з неврологічними проявами остеохондрозу хребта. За механізмом розвитку цього захворювання тракція хребта - найбільш фрізіологічно обгрунтований захід [10, 14, 16].

Сутність тракції полягає в тому, що за допомогою короткочасної або тривалої тяги долається м'язовий спазм, усувається зміщення хребців, деформація вигинів хребта [9].

Реабілітаційні заходи в системі консервативного лікування мають низку істотних переваг i, головне, будучи профрілактичними, дозволяють не використовувати оперативне втручання, а стабілізувати патологічні зміни хребта і навіть зменшити їх. I хоча кожний із вище перерахованих методів $\epsilon$ високоефективним, однак стійкий терапевтичний ефект можна одержати тільки у поєднанні їх із заняттями терапевтичними вправами, що забезпечить створення повноцінного м'язового корсета $[10,11,18]$. Для подальшого поновлення активної життєдіяльності пацієнта необхідна ефрективна фрізична терапія, що сприяла б відновленню як функції хребта, так і поліпшенню загального стану хворого.

Мета роботи - дослідити ефективність застосування тракції та кінезитерапії в лікуванні дегенеративних змін у поперековому відділі хребта.

Матеріали та методи досліджень. Робота виконана на матеріалі ДУ «Інститут травматології та ортопедії НАМН України» і включає аналіз обстеження та лікування 46 хворих -28 жінок і 18 чоловіків з клінічними і морфологічними проявами гриж міжхребцевих дисків поперекового відділу хребта. Морфологічні зміни оцінювали за даними КТ та / або МРТ.

Середній вік пацієнтів становить 35-55 років. Всі пацієнти були клінічно обстежені (обстеження неврологічного статусу); кількісну та якісну оцінка больового синдрому здійснювали на підставі ВАШ (візуальної аналогової шкали); досліджено час проходження дистанції 50 м і впевненість ходи (за 10-бальною шкалою). Для оцінки ступеня порушення життєдіяльності, обумовленого патологією хребта, використовували анкетування за Oswestry.

Пацієнти були поділені на основну і контрольну групи. Пацієнти основної групи у поєднанні з курсом медикаментозного лікування проходили курс тракційної терапії та кінезитерапії на базі відділення реабілітації з подальшими рекомендаціями із дотримання рухового режиму на постклінічному етапі; пацієнти контрольної групи проходили тільки курс медикаментозного лікування та кінезитерапії в стаціонарі.

Методика апаратної тракції базується на застосуванні інтермітуючого режиму. Під час процедури найбільш оптимальною $€$ поза нейтрального положення хворого, при якій унеможливлюється натягування сухожилкового i м'язово-зв'язкового апарату. Інтермітуючий режим здійснювали із зменшенням заданого зусилля на 25-50\% у кожному циклі, при зміні експозиції (від 30-60 с на максимумі до 1-2 хв на мінімумі). Початкове навантаження не перевищувало 5-6 \% від маси тіла пацієнта. Максимальне зусилля не перевищувало початкове більше ніж у 1,5-2 рази, приріст маси вантажу становив 0,51 кг, а тривалість $-10-12$ хв. Курс тракційного лікування складався з 7-10 процедур, щоденно. 
Протягом 2-3 процедур тракційне зусилля зростало до максимального, що визначалось індивідуально, з 4-ї по 7-у процедури проводились при максимальній силі тракції, у потім, у процесі подальших 2-3 процедур ії̈ знижували. Тривалість процедури зростала поступово - від 10-15 до 20-30 хв.

Слід враховувати, що в початковій фразі тракційного впливу настає рефлекторне захисне напруження м'язів. Приблизно через 5-10 хв воно зникає, і лише в цій фразі можна говорити про тракційне зусилля, яке впливає на суглоб. Ось чому важливо повільно збільшувати силу тракції і використовувати досить тривале витягування. Курс лікування слід перервати або переглянути схему витягнення, якщо під час або після процедури значно посилюється біль або з'являються ознаки невропатії.

Післятракційний період включав фріксацію сегмента в корсеті у поєднанні з активним м'язовим захистом за допомогою вправ, які виконували в ізометричному режимі та на похилій площині через 20-30 хв після закінчення тракції.

Після закінчення курсу тракцій хворим із нейрокомпресійним больовим синдромом попереково-крижового відділу хребта проводили терапевтичні вправи на фрітболі. Вихідні положення (в. п.) - лежачи на м'ячі на спині, на животі, сидячи. Використовували дихальні, статичні, загальнорозвиваючі, коригуючі вправи, спеціальні вправи для розслаблення м'язів. Кількість процедур - 12, через день. При задовільному стані хворих рекомендували подальше розширення рухового режиму за індивідуальною програмою: 3 використанням фрітболів, баланс-платформ, BOSU для корекції порушень статодинамічного стереотипу. В. п. - лежачи на спині, на животі, стоячи. Застосовували вправи на BOSU у в. п. сидячи, стоячи на колінах, стоячи. Згодом додавали вправи на розвиток сили м'язів тулуба та нижніх кінцівок з обтяженнями. Тривалість процедури 30-45 хв. Кількість процедур - 14, через день.

Основні цілі застосування терапевтичних вправ визначалися індивідуально залежно від стану ОРА хворого: усунення больового синдрому, корекція вертеброгенних ресрлекторних деформацій, зміцнення м'язів тулуба і кінцівок з метою звільнення хворого від носіння ортопедичного корсета.

Результати досліджень та їх обговорення. Клінічне обстеження продемонструвало, що всі пацієнти скаржилися на безперервний виражений біль у поперековому відділі хребта з іррадіацією в одну або обидві ноги, який посилювався під час ходьби або фрізичного навантаження.
Спортивна медицина і фізична реабілітація, №2, 2017

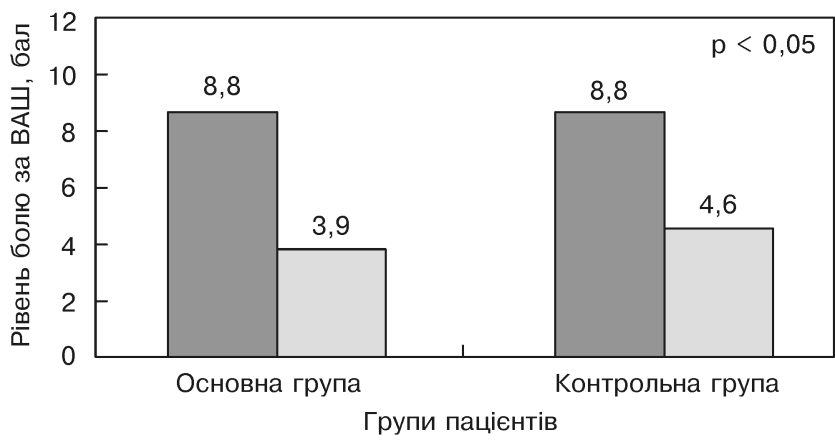

Рисунок 1 - Рівень больового синдрому за даними ВАШ в основній та контрольній групах до та після лікування:

$\square-$ до лікування; $\square-$ після лікування

Середня тривалість захворювання становила 4,1 $\pm 0,5$ року, кількість загострень на рік $1,2 \pm 0,3$ раза, тривалість останнього загострення $-0,8 \pm 0,6$ міс.

В обох групах продемонстрована позитивна динаміка. Так, за даними ВАШ, під час первинного обстеження пацієнтів рівень больового синдрому в середньому дорівнював 8,8 \pm 0,7 бала. Після проведення курсу лікування позитивна динаміка спостерігалася у пацієнтів обох груп (у контрольній групі $-4,6 \pm 0,5$ бала, в основній групі - 3,9 $\pm 0,6$ бала; $p \leq 0,05$ ) (рис. 1).

Після проведеного курсу лікування більш впевненими під час ходьби почувалися пацієнти основної групи (рис. 2).

Час проходження дистанції 50 м до та після проведеного курсу лікування у пацієнтів основної групи становив: на початку лікування -43 с, після лікування - 25 с. У контрольній групі: на початку лікування - 44 с, після проведеного лікування - 30 с (рис. 3).

Оцінка результатів лікування 3 використанням стандартизованого анкетування за Oswestry, що відображає ступінь порушення життєдіяльності, - у відсотковому співвідношенні кращий результат був у пацієнтів основної групи (рис. 4).

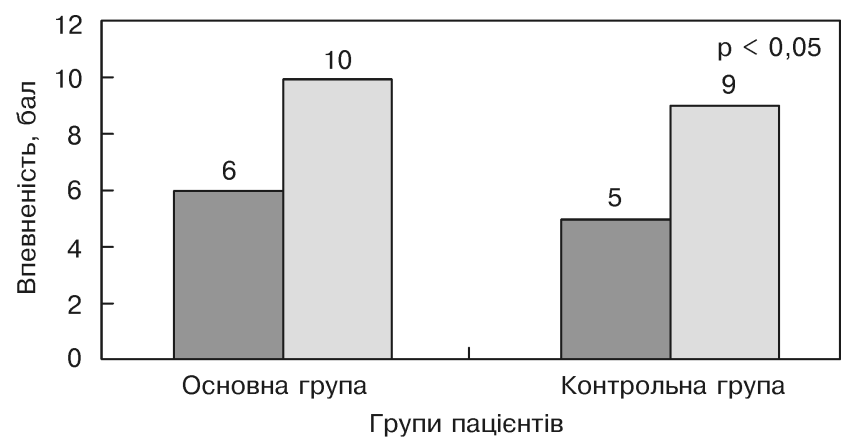

Рисунок 2 - Динаміка тесту впевненості ходьби за 10-бальною шкалою:

$\square$ - до лікування; $\square-$ після лікування 
Спортивна медицина і фізична реабілітація, № 2, 2017

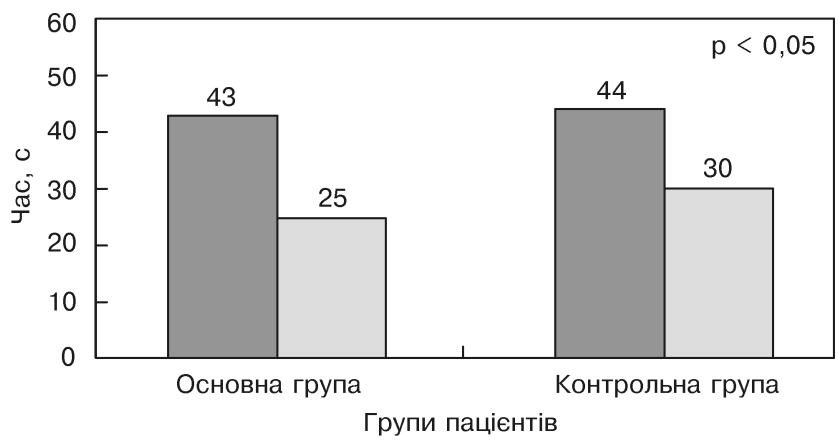

Рисунок 3 - Час проходження дистанції 50 м після проведеного курсу:

$\square$ - до лікування; $\square-$ після лікування

Висновки. Застосування тракції у поєднанні з медикаментозним лікуванням і терапевтичними вправами у пацієнтів з дегенеративними змінами в поперековому відділі хребта дозволяє підвищити ефрективність лікування, що підтверджується результатами досліджень. Проводити ії вкрай

\section{Література}

1. А. с. 1739991 Страна, МКИ А $61 \mathrm{~F} 5 / 02$. Устройство для вытяжения позвоночника / Д. К. Макридин. - № 4611130/14; Заявлено 30.11.1988. Опубл. День. месяц. 1992; Бюл. № 22. - С. 23.

2. Абдуразаков А. У. Лечение поясничного остеохондроза различными видами вытяжения / А. У. Абдуразаков, И. Н. Есмембетов // Здравоохранение Казахстана. - 1991. - № 11. - С. 59-60.

3. Белова А. Н. Нейрореабилитация : рук. для врачей । А. Н. Белова. - М. : Антидор, 2000. - 567 с.

4. Епифанов В. А. Восстановительное лечение при заболеваниях и повреждениях позвоночника / В. А. Епифанов, А. В. Епифранов. - М. : МЕДпресс-информ, 2008. - 384 с.

5. Петухов В. Н. Взаимосвязь различных величин дистракции и жесткости фиксации при лечении поясничного остеохондроза методом горизонтального вытяжения / В. Н. Петухов // Вестн. травматол. и ортопед. им. Н. Н. Приорова. - 2000. - № 3. - С. 50-56.

6. Попелянский Я. Ю. Ортопедическая неврология (вертеброневрология) : рук. для врачей / Я. Ю. Попелянский. - 3-е изд. - М. : МЕДпрессинформ, 2003. - 672 c.

7. Beurskens A. J. Efficacy of traction for nonspecific low back pain / A. J. Beurskens, H. C. de Vet, A. J. Kooke, W. Regtop et al. // Spine. - 1997. N 22 (23). - P. 2756-2762/

8. Fishchenko $Y$. Y. The evaluation of the results of nonsurgical treatment of patients with lumbar stenosis formed after degenerative deformations in the lumbar spine / Y. Y. Fishchenko, O. A. Perepechay, L. D. Kravchuk // The J. of Traumatology and Orthopedics. - 2015. - N 1-2. - P. 31-32.

9. Krause M. Lumbar spine traction: evaluation of effects and recommended application for treatment / M. Krause, K. M. Refshauge, M. Dessen, R. Boland // Manual Therapy. - 2000. - N 5 (2). - P. 72-81.

10. Lazarieva $O$. Physical rehabilitation of low back pain based on a conceptual system approaches / O. Lazarieva, M. Cieślicka, B. Stankiewicz, R. Muszkieta, K. Prusik // Pedagogics, psychology, medical-biological problems of physical training and sports. - Kharkiv, 2014. - N 11. P. 74-78.

11. Lazarieva $\mathrm{O}$. The strategical frameworks of the physical rehabilitation in surgical treatment of the patients with low back pain / O. Lazarieva, M. Cieślicka, B. Stankiewicz, R. Muszkieta, K. Prusik // Pedagogics, psycholo-

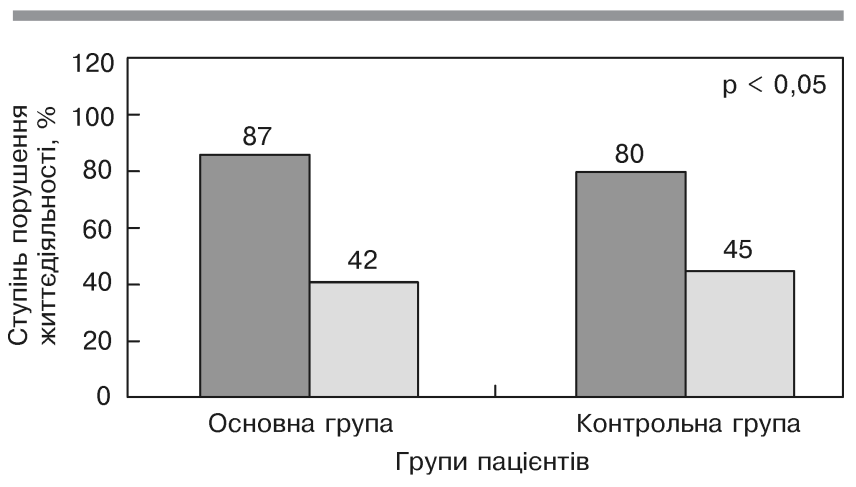

Рисунок 4 - Динаміка лікування за результатами стандартизованого анкетування Oswestry у порівнянні основної і контрольної груп:

$\square$ - до лікування; $\square-$ після лікування

бажано в спеціальних реабілітаційних стаціонарах, де $\epsilon$ висококваліфіковані фрахівці, напрацьовані лікувальні методики та відповідні умови проведення лікування. Означений підхід дозволяє досягти максимального функціонального результату.

\section{References}

1. A. S. 1739991 Country, ICC A 61 F 5/02. Device for spinal traction I D. K. Makridin. - N 4611130/14; It is declared on 30.11.1988. Opubl. Day. month. 1992; Bul. N 22. - P. 23

2. Abdurazakov, A.U., \& Esmembetov, I.N. (1991). Lecheniye poyasnichnogo osteokhondroza razlichnymi vidami vytyazheniya [Treatment of lumbar osteochondrosis by various types of traction]. Zdravookhraneniye Kazakhstana - Healthcare of Kazakhstan, 11, 59-60 [in Kazakhstan].

3. Belova, A.N. (2000). Neyroreabilitatsiya [Neurorehabilitation]. Moscow: Antidor [in Russian]

4. Epifanov, V.A., \& Epifanov, A.V. (2008). Vosstanovitel'noye lecheniye pri zabolevaniyakh i povrezhdeniyakh pozvonochnika [Restorative treatment for diseases and injuries of the spine]. Moscow: MEDpress-inform [in Russian].

5. Petukhov, V.N. (2000). Vzaimosvyaz' razlichnykh velichin distraktsii i zhestkosti fiksatsii pri lechenii poyasnichnogo osteokhondroza metodom gorizontal'nogo vytyazheniya [Interrelation of different values of distraction and stiffness of fixation in the treatment of lumbar osteochondrosis by the method of horizontal extension]. Vestnik travmatologii i ortopedii imeni N.N. Priorova Herald of Traumatology and Orthopedics named after N.N. Priorov, 3, 50-56 [in Russian].

6. Popelyansky, Ya.Yu. (2003). Ortopedicheskaya nevrologiya (vertebronevrologiya) [Orthopedic neurology (vertebroneurology)]. (3rd ed.). Moscow: MEDpress-inform [in Russian].

7. Beurskens, A.J., de Vet, H.C., Kooke, A.J., Regtop, W., Van der Heijden, G.J., Lindeman, E., \& Knipschild, P.G. (1997). Efficacy of traction for nonspecific low back pain. Spine, 22 (23), 2756-2762.

8. Fishchenko, Y.Y., Perepechay, O.A., \& Kravchuk, L.D. (2015). The evaluation of the results of nonsurgical treatment of patients with lumbar stenosis formed after degenerative deformations in the lumbar spine. The $\mathrm{J}$. of Traumatology and Orthopedics, 1-2, 31-32 [in Ukrainian].

9. Krause, M., Refshauge, K.M., Dessen, M., \& Boland, R. (2000). Lumbar spine traction: evaluation of effects and recommended application for treatment. Manual Therapy, 5 (2), 72-81.

10. Lazarieva, O., Cieślicka, M., Stankiewicz, B., Muszkieta, R., \& Prusik, K. (2014). Physical rehabilitation of low back pain based on a conceptual system approaches. Pedagogics, psychology, medical-biological problems of physical training and sports, 11, 74-78 [in Ukrainian]. 
gy, medical-biological problems of physical training and sports. - Kharkiv, 2014. - N 12. - P. 70-74.

12. McGill S. M. Is a postural-structural-biomechanical model, within manual therapies, viable : AJBMT debate / S. M. McGill // Invited Response J. Bodywork and Movement Therapy. - 2011. - N 15 (2) . - P. 150-152.

13. Meszaros T. F. Effect of $10 \%, 30 \%$ and $60 \%$ body weight traction on the straight leg raise test of symptomatic patients with low back pain I T. F. Meszaros, R. Olson, K. Kulig, D. Creighton, E. Czarnecki // J. Orthop. Sports Phys. Ther. - 2000. - Vol. 30, N 10. - P. 595-601.

14. Nordin M. Physical medicine, traction, exercise and revalidation // Brussels International Spine Symposium. Abstract book. - Brussels, 2000. P. 28-29.

15. Pasichnyk V. M. Therapeutic exercises as an essential part of the physical rehabilitation during the low back pain / V. M. Pasichnyk // The J. of Education, Psychology and Medical and Biological Problems of the Physical Education and Sport. - 2010. - N 7. - P. 76-79.

16. Pellecchia G. L. Lumbar traction: a review of the literature / G. L. Pellecchia // J. Orthop. Sports Phys. Ther. - 1994. - Vol. 20, N 5. - P. 262-267.

17. Povorozniuk V. V. The low back pain: distinctness, causes, mechanisms of development and diagnostic features / V. V. Povorozniuk // Pain, Joints and Spinal J. - 2011. - N 1. - P. 13-22.

18. Zharova I. A. The relationship between the development of static flatfoot and back pain in the individuals of different age groups / I. A. Zharova // The J. of Physical Education of the Students. - 2003. - N 7. - P. 81-89.

katiukova@ukr.net
Спортивна медицина і фізична реабілітація, № 2, 2017

11. Lazarieva, O., Cieślicka, M., Stankiewicz, B., Muszkieta, R., \& Prusik, K. (2014). The strategical frameworks of the physical rehabilitation in surgical treatment of the patients with low back pain. Pedagogics, psychology, medical-biological problems of physical training and sports, 12, $70-74$ [in Ukrainian].

12. McGill, S.M. (2011). Is a postural-structural-biomechanical model, within manual therapies, viable: AJBMT debate. Invited Response J. Bodywork and Movement Therapy, 15 (2), 150-152.

13. Meszaros, T.F., Olson, R., Kulig, K., Creighton, D., \& Czarnecki, E. (2000). Effect of $10 \%, 30 \%$ and $60 \%$ body weight traction on the straight leg raise test of symptomatic patients with low back pain. J. Orthop. Sports Phys. Ther., 10 (30), 595-601.

14. Nordin, M. (2000). Physical medicine, traction, exercise and revalidation. Brussels International Spine Symposium. Abstract book, 28-29. Brussels.

15. Pasichnyk, V.M. (2010). Therapeutic exercises as an essential part of the physical rehabilitation during the low back pain. The J. of Education, Psychology and Medical and Biological Problems of the Physical Education and Sport, 7, $76-79$ [in Ukrainian].

16. Pellecchia, G.L. (1994). Lumbar traction: a review of the literature. J. Orthop. Sports Phys. Ther., Vol. 20, 5, 262-267.

17. Povorozniuk, V.V. (2011). The low back pain: distinctness, causes, mechanisms of development and diagnostic features. Pain, Joints and Spinal J.1, 13-22.

18. Zharova, I.A. (2003). The relationship between the development of static flatfoot and back pain in the individuals of different age groups. The $\mathrm{J}$. of Physical Education of the Students, 7, 81-89 [in Ukrainian].

Надійшла 20.07.2017 